\title{
Ancient Modes of Inland Water Transportation in Sri Lanka: Stability Analysis on Craft Excavated from Attanagalu Oya.
}

\section{Jayawardana}

\begin{abstract}
Strategic location of Sri Lanka in ancient marine routes and the availability of natural sea ports around its shore line, was a well established fact. Marine archeological findings surfaced recently prove Sri Lanka's engagement in maritime navigation from early periods. Apart from oceanic transport, numerous internal water ways also have contributed to the ancient water transport facilities in a noteworthy manner. Socio cultural consequences due to both oceanic and inland water transport have been studied comprehensively and a vast amount of research literature is now available in that context. But the study of technological aspects of ancient water transportation modes is a highly limited area.
\end{abstract}

This paper is devoted to explore some historical references of the inland water transport crafts and stability analysis of one of the specimens excavated from inland water ways and now conserved at Colombo National Museum.

Key words: maritime navigation, inland water transport, buoyancy, stability of water crafts

\section{Introduction}

Sri Lanka has played a role as a great trade centre of long distance maritime trade from preChristian era. Apart from the trading activities, political and religious purposes have also played vital roles in establishing Sri Lanka as a major destination of many ancient authorities. Tenant [1], Gunawardana [2] and Bopearachchi [3] record extensive foreign relations with Greeks, Roman, Indian, Arabian, Persian, Chinese, Moors, Genoese and Venetian authorities had with ancient Sri Lanka.

\section{Importance of Inland Water Transport}

Bopearachchi [3] further evaluating the contribution of internal water ways in international trade, notes many of the ancient Sri Lankan ports are situated at the estuaries of rivers. Some examples for such locations are, Salavathura [Chillaw] at the Deduru Oya, Wattala at the Kelani Ganga, Kalatittha [Kaluthara] at the Kalu Ganga, Bhimatittha [Benthota] at the Bentota Ganga, Gimatittha [Ginthota] at the Gin Ganga, Mahavalukagama [Weligama] at the Polwatta Ganga, Nilwalatittha [Matara] at the Nilvala Ganga, Gothapabbatha [Godavaya] at the Walave Ganga and Kirinda at the Kirindi Oya.

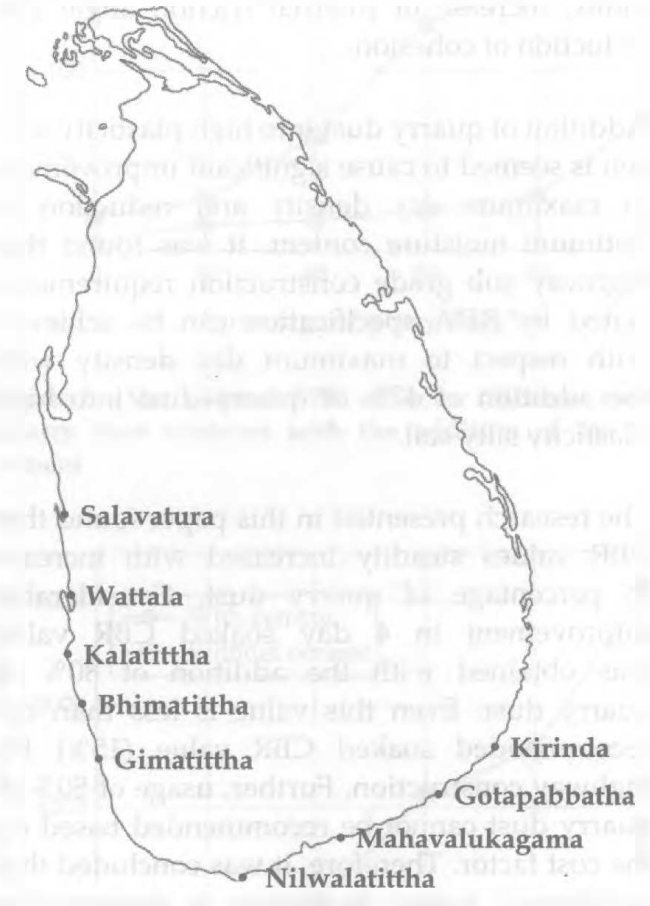

Fig 1: Ancient Sri Lankan ports associated with river estuaries

Eng. C Jayawardana, [B.Sc (Eng)Hons, MTech, MA, MIET, MIE (Sri Lanka), C.Eng], presently a Project Manager, Cruicksianks Ceylon Pvt. Lid. Katunayaka 
Fig. 1 showing the distribution of these ancient ports, clearly highlights the close relationship between the ports and the estuaries of $r$ ers. This implies that trade activities of ancient Sri Lanka was not solely maritime, but also had a contribution from inland waterway transport. Import and export activities connected with the sea ports would have been mainly a result of their situation at the river mouths linking them with inland production centers.

Vitharana [4] notes a variety of references for inland water crafts that could be located in classical Sinhala literary work, at least from 10th century AD. The Dhampiya Atuva Getapadaya of 10th century AD and Muvadevdavatha refer to pasura or pahura [raft]. The Jathaka Atuva Getapada and Buthsarana both of 12th century $\mathrm{AD}$, refer to angula or hangula, [the double canoe]. Saddharmarathnavaliya of 13th century $\mathrm{AD}$ and Saddharmalankaraya of the 14th century AD refer to padav [lighter]. Hamsa Sandesaya of 15th century AD and Papiliyana inscription of 18th century $\mathrm{AD}$ refer to paru [barges]. Milindaprasnaya of 18th century AD refers to sampan or hamban [smack]. The word hour or oru [dug out outer rigger canoes] occur in the Dhampiya Atuva Getapadaya, Buthsarana, Dhammapradeepika and Ruwanmal Nigantuwa of early 15th century AD. Considering this vast amount of literary evidences, and the diversification of transport modes, it could be concluded that a well established inland water transport system prevailed from the ancient times.

Apart from the water ways evident in present times, there might have been hydraulic structures which existed in ancient times and vanished due to some reasons. Mendis [5] noting the references in Chulvamsa to a mega scale reservoir Parakrama Sagara, identifies this as the greatest achievement of king Parakramabahu I (1153$1186 \mathrm{AD})$, although it is not in current existence. This consisted consisting of seven adjacent reservoirs of which Koththabadhdhanijjara, the first and the greatest, which was formed by raising the Elahera anicut. These reservoirs were connected by means of six locks between adjacent reservoirs which made the Elahera channel navigable despite a drop of sixty feet from Elahera to Minneriya.

According to Brohier, boats used to ply from far away from Minipe on the main Mahaweli Ganga to Elahera on the Abanganga, and then via Minneriya, Gantalawa and Tambalagamam bay to sea at Trincomalee. The ancient tamarind tree, which is popularly known as oru bendi siyambalawa on the bund between Elahera and Minneriya was reported to be used to anchor the crafts thus navigated.

It is in the context of the above the background, that a nautical engineering analysis of ancient inland water crafts, is a worthy exercise and will widen the horizons of present understanding on the subject.

\section{Archeological Sources}

Specimens of ancient water crafts have been surfaced in three different locations in the island. Two of them, specimen 1 and 2 below, are now in the display in Colombo National Museum and specimen 3 is at Rathnapura museum. The details of these specimens are as below.

\subsection{Specimen 1}

This is a dug out type canoe, first salvaged from the bottom of the Kelani Ganga, at Malvana ferry, in 1952. At each end of the hollow, a cross wise ridge is evident at the bottom. Its purpose is not explained because its like is not repeated in the present day dug-out canoes. There is no evidence [such as a row of small holes bored along the edge] to the erstwhile presence of washstrakes. There are three pairs of holes on either sides of the hull. Vitharana concludes the outermost pairs were meant to lash a boom, but the presence of three such pairs forms a question as only two booms are employed in present day dug-out canoes.

On both sides of the bottom are cracks, and parts of the wood have weathered off. At both ends of the hull, there are two holes and the purpose of these holes is not ascertained so far. The construction material has been identified as rata del [artocarpus incisa]. According to the calibrated dating obtained from C14 analysis, this has been placed chronologically between 400-200BC. 


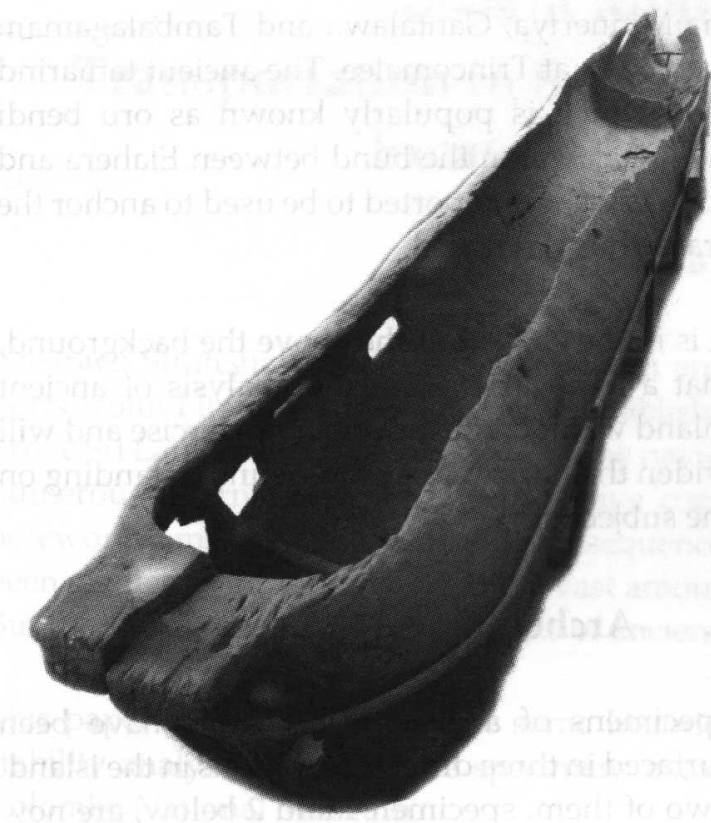

Fig.2: The remains of water craft excavated from Kelani Ganga

\subsection{Specimen 2}

The remains of a water craft found from Attanagalla, is a rare specimen of ancient craft work. This was located from the banks of Aattanagalu oya, a tributary of the Kelani Ganga, at Attanagalla Regional Secretarial Division. The place of location was a property of Pabovita Raja Maha Viharaya. This was identified as a water craft only in December 1998, and similar objects are said to be still lying in the vicinity.

The dimensions and shape are as fig 8. In the present condition, the front is having a pointed end and at the back, a blunt. Somasiri Devendra, doing a special investigation on this craft, concludes that originally both ends were having a similar shape with pointed ends. There is a hole in one side of the hull, which might be used for holding to a stand. The interior has been divided into several compartments, of which the purpose is still to be established. One possible reason expressed is to facilitate the transport of passengers or goods.

The construction material has been identified as hora [dipterocarpus zeylanicus]. According to calibrated dating obtained from $\mathrm{C} 14$ analysis by the beta analytic laboratory in Florida, this craft has been placed chronologically between 670 790AD.
Remains of another ancient water craft is available at Rathnapura Museum, which is said to be surfaced from a gem pit in the area.

\section{Hydrostatic Conditions for Water Crafts}

\subsection{Conditions for Buoyancy}

For a water craft to be floatable, it must maintain a delicate balance between buoyancy and stability. Under the buoyancy conditions the buoyancy force, which similar to the weight of the water mass displaced by the craft should be in balance with the weight of the craft. If the craft is too light, it.will bob on the top of the water. Therefore, it needs to carry a certain amount of ballast, if its own weight is not sufficient to provide the required amount of stability. These conditions are as illustrated in fig. 3.

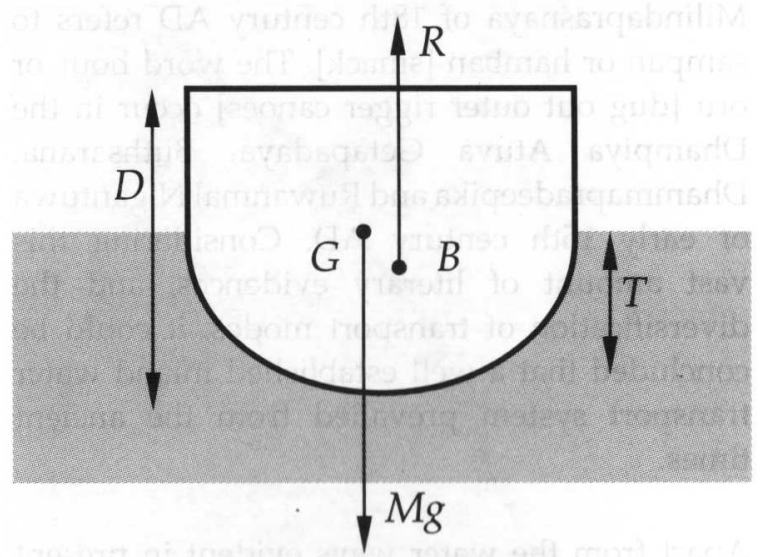

Fig. 3. Forces acting on a floating body, G and B separated for clarity

Considering the vertical stability of the craft,

$\mathrm{Mg}=\mathrm{R}=\rho_{\mathrm{w}} \mathrm{Vg}$

Where,

$\mathrm{M}=$ Mass of the craft

$\mathrm{R}=$ Buoyancy force

$\rho_{w}=$ Density of water

$\mathrm{V}=$ Volume of water deplaced by the craft

$\mathrm{g}=$ Gravitational acceleration

$\mathrm{G}=$ Center of gravity

$\mathrm{B}=$ Center of buoyancy

Draught, $\mathrm{T}$ is obviously depending on the mass, $\mathrm{M}$. The maximum loading of the craft and its constituents will reach when $T=D$, the depth of the craft. 
Stability is the resistance of a craft to forces that tend to induce heeling. These forces are usually static, like wind pressure on the sails or unbalanced loading, but storm conditions can introduce dynamic forces like wind gusts and breaking waves. Evaluating the overall stability, requires the consideration of both static and dynamic stability issues, but as the specimen under consideration is meant only for inland water ways where wind forces are minimal, and in the absence of the usage of sails, only the static stability will be considered under the scope of this paper.

Metacenter, $\mathrm{C}$ is defined as the intersection of two successive lines of action of the force of buoyancy, as the craft heels through a very small angle. Fig. 4 indicates the relative positions of $G$, $B$ and $C$ for a small heel angle of $\theta$. Muckle [6] notes the initial position of the metacenter is most useful in the study of stability, as it provides a reference point when craft is upright and most stable. For craft to be stable, $\mathrm{C}$ should be above $G$, thus condition for stability GC>0.

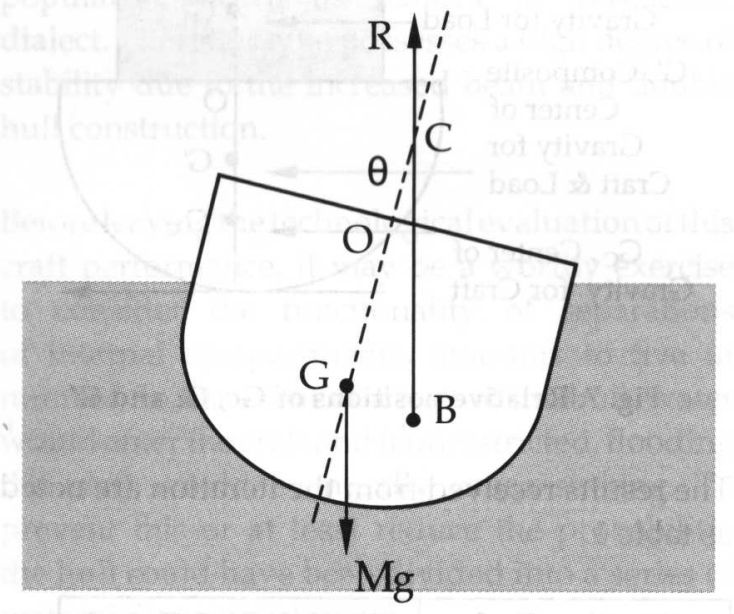

Fig. 4 Relative positions of G, B and C for stable condition

According to hydrostatic principles,

$\mathrm{BC}=\mathrm{I} / \mathrm{V}$

Where,

$\mathrm{I}=$ Second moment of area of water plane about center line

$\mathrm{V}=$ Volume of water replaced by the craft

And considering the geometry when the craft is on even keel, i.e $\theta=0$,
$\mathrm{GC}=\mathrm{BC}-\mathrm{GB}$

Where

$\mathrm{GC}=$ Metacentric height

$\mathrm{BC}=$ Metacentric radius

For the craft's initial stability, GC>0

\section{Application to Specimen 2}

\subsection{Condition for No-load Buoyancy}

Based on the measurements taken, drawing no. 1 was generated for specimen no. 2 and the equations derived in preceding chapter will be applied for buoyancy and stability analysis. A cross sectional area at the amidships was considered as fig. 5. From the actual measurements, best fit curves for inner and outer profiles of the craft were developed. The equations thus received are,

For outer profile, $y=2.9 x^{2.6}$

For inner profile, $y=0.13+1.45 x^{2}$

Finding the mass of the craft under unloaded condition,

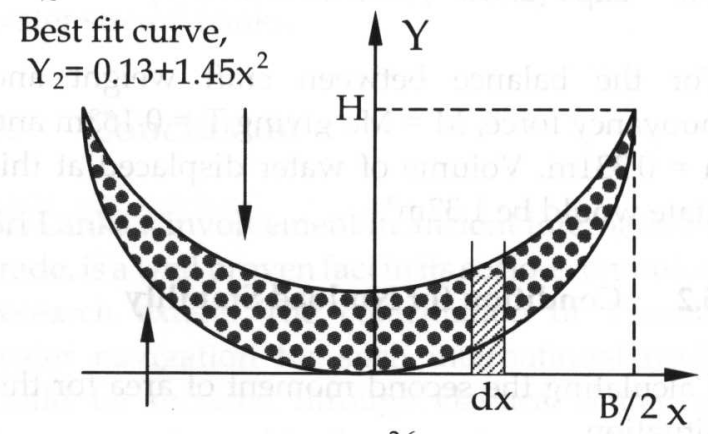

Best fit curve, $Y_{1}=2.9 x^{2.6}$

Fig. 5. Cross section view of the uniform part of the hull

According to Eq.1, mass of the craft, $\mathrm{M}$

$\mathrm{M}=2 \mathrm{~L} \rho_{\mathrm{c}} \int_{0}^{\mathrm{B} / 2}\left(\mathrm{Y}_{2}-\mathrm{Y}_{1}\right) \mathrm{dx}$

Simplifying,

$M=L \rho_{c}\left(0.13 B+0.12 B^{3}-0.13 B^{3.6}\right)$

Where,

$\mathrm{L}=$ Length between perpendiculars

$\mathrm{B}=$ Breadth moulded

$\rho_{c}=$ Density of craft material

Substituting $\mathrm{L}=17 \mathrm{~m}, \mathrm{~B}=1 \mathrm{~m}$ and $\rho c=660 \mathrm{~kg} / \mathrm{m}^{3}$ gives $M=1324 \mathrm{~kg}$ 


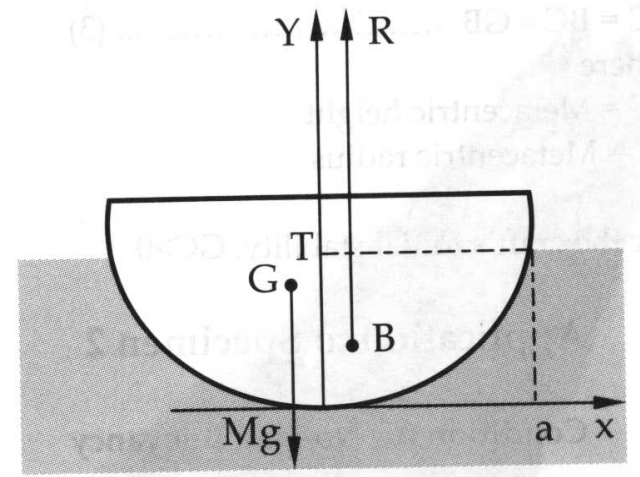

Fig. 6. Draught level of the craft under the loading

Finding the draught of the craft under unloaded condition,

Mass of the water volume displaced by the craft, $\mathrm{Mw}$

$\mathrm{M}_{\mathrm{w}}=2 \mathrm{~L} \rho_{\mathrm{w}} \int_{0}^{\mathrm{a}}\left(\mathrm{T}-\mathrm{Y}_{1}\right) \mathrm{dx}$ and $\mathrm{T}=2.9 \mathrm{a}^{2.6}$

where,

$\mathrm{T}=$ Draught

$\mathrm{a}=$ Distance between the centerline and the water line under unloaded condition

Simplifying,

$\mathrm{M}_{\mathrm{w}}=2 \mathrm{~L} \rho_{\mathrm{w}}\left(2.09 \mathrm{a}^{3.6}\right)$

For the balance between craft weight and buoyancy force, $\mathrm{M}=\mathrm{M}_{\mathrm{w}}$ giving $\mathrm{T}=0.163 \mathrm{~m}$ and $\mathrm{a}=0.331 \mathrm{~m}$. Volume of water displaced at this state would be $1.32 \mathrm{~m}^{3}$.

\subsection{Condition for No-load Stability}

Calculating the second moment of area for this situation,

$\mathrm{I}=\mathrm{L}(2 \mathrm{a})^{3} / 12=0.409 \mathrm{~m}^{4}$

According to Eq.2, BC $=0.309 \mathrm{~m}$

Calculating the heights from $\mathrm{O}$ to $\mathrm{G}$ and $\mathrm{B}$,

$O G=0.293 \mathrm{~m}$ and $\mathrm{OB}=0.371 \mathrm{~m}$, gives

$\mathrm{BG}=0.078 \mathrm{~m}$

According to Eq.3, GM $=0.231 \mathrm{~m}$ which is $>0$ From above values it is evident that the craft is stable at the no-load condition and will float with $0.163 \mathrm{~m}$ draught.

\subsection{Calculation for Loaded Conditions}

Taking total weight of the craft after loading, $\mathrm{M}_{\mathrm{T}}=1324+\mathrm{ML}_{\mathrm{L}}$

Where

$\mathrm{M}_{\mathrm{T}}=$ Total mass of the craft,
$\mathrm{ML}_{\mathrm{L}}=$ Mass of the cargo, operators and their operating gear.

Considering the maximum loading value and mass of the unloaded craft,

$\mathrm{M}_{\text {Tmax }}=1324+\mathrm{MLmax}_{\text {max }}$

From Eq. 4,

$\mathrm{M}_{\mathrm{Tmax}}=2 \mathrm{~L} \rho_{\mathrm{w}}\left(2.09(\mathrm{~B} / 2)^{3.6}\right)$

Substituting $\mathrm{L}=17 \mathrm{~m}, \rho_{\mathrm{w}}=1000 \mathrm{~kg} / \mathrm{m}^{3}, \mathrm{~B}=1 \mathrm{~m}$ gives this craft could be loaded to a maximum load of MLmax $=4680 \mathrm{~kg}$

Apart from the load mass, it is important to consider the center of gravity of the load also, as that will affect the height GC. To evaluate this effect, the composite center of gravity $\mathrm{G}^{\prime}$, formed by the craft and load was considered. An iterate process was followed to find the maximum height between $\mathrm{O}$ and the center of gravity of the load, so that the condition for stability $\mathrm{G}^{\prime} \mathrm{C}>0$ could be maintained.

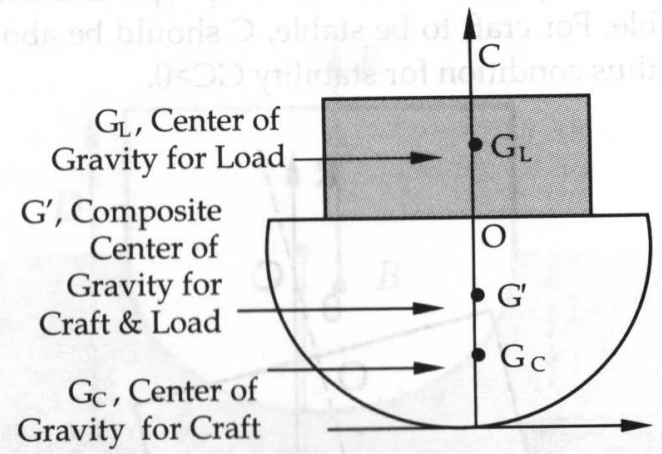

Fig. 7. Relative positions of Gc, GL and G'

The results received from the iteration are noted as table 1 .

\begin{tabular}{|c|c|}
\hline Loading $[\mathrm{kg}]$ & Maximum $\mathbf{O G}_{\mathbf{L}}[\mathrm{m}]$ \\
\hline 500 & 0.595 \\
1000 & 0.305 \\
1500 & 0.222 \\
2000 & 0.188 \\
2500 & 0.175 \\
3000 & 0.172 \\
3500 & 0.174 \\
4000 & 0.180 \\
4500 & 0.188 \\
\hline
\end{tabular}

Plotting of the above values, gives graph 1 below. 


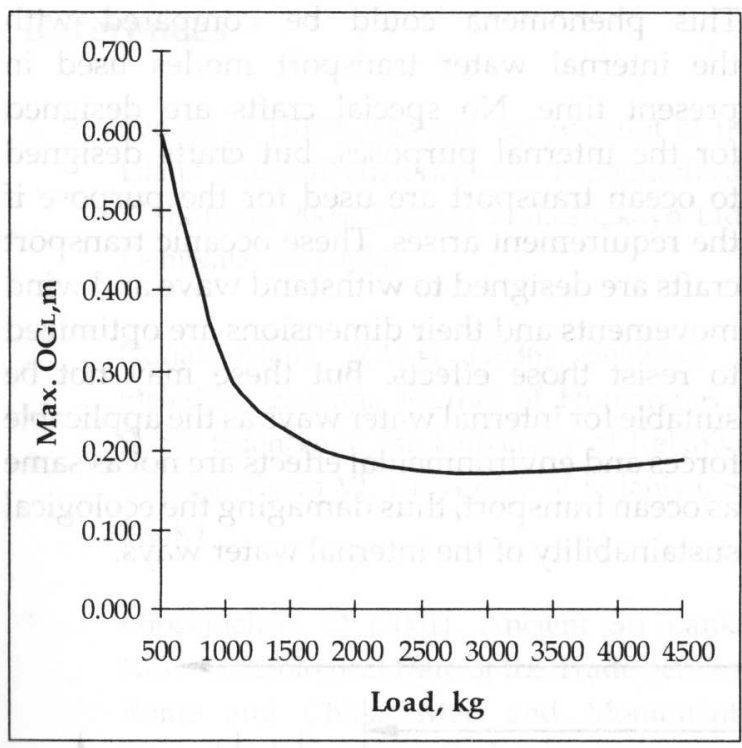

Graph 1 Maximum allowable OG' vs Load, for the stability of the craft

Rather low values of OGL [exa. for a load of $2500 \mathrm{~kg}$, OGL is just $15 \mathrm{~cm}$ above the gunwale] suggest that usage of this specimen as a single hull dug out type canoe is very remote. Instead this could be a part of double hull canoe, popularly known as pahura in vernacular dialect. This later type possesses a high degree of stability due to the increased beam and double hull construction.

Before leaving the technological evaluation of this craft performance, it may be a worthy exercise to consider the functionality of separations of internal compartments, amounts to five in number. In the event of a leak of the hull, water would enter the craft and if unrestricted, flooding the craft would eventually cause sinking. To prevent this or at least reduce the probability, the hull could have been divided into a series of water tight compartments.

Another contribution of these partitions would be to provide the required structural strength for the hull, as these are the left over parts of the same log which formed the hull. The bottom would have been structurally weak due to its long span, thus requiring some form of reinforcement. These partitions would act as reinforcing cross members.

\section{Environmental evaluation}

Apart from the load bearing and stability analysis, it is also important to consider any underlying environmental impacts of inland waternavigation. The results of ajoint experiment by NERD and University of Peradeniya are of importance in this context. The experiment was designed to compare the wave formation by single hull canoe and double hull dug out type canoe, both having the same loading capacity. A mathematical model for wave formation was formed by dimension analysis,

$\mathrm{H}_{\mathrm{w}} / \mathrm{L}=\mathrm{f}\left(\mathrm{V}^{2} / \mathrm{gL}\right)$

Where,

$\mathrm{H}_{\mathrm{w}}=$ Wave amplitude at a given distance from the moving craft

$\mathrm{L}=$ Length of the craft

$\mathrm{V}=$ Velocity of the craft

$\mathrm{g}=$ Gravitational acceleration

Two models scaled down to 30:1 were constructed in such a way that both types of crafts could accommodate the same load under the maximum displacement. It was noted at a distance of $30 \mathrm{~m}$ from the craft, the single hull canoe generated water waves with the amplitude of $45 \mathrm{~cm}$ while that of double hull canoe was only $15 \mathrm{~cm}$. This leads to conclude that the latter type minimizes the wave formation, thus erosion of water stream banks.

\section{Conclusion}

Sri Lanka's involvement in ancient international trade, is a well proven fact in its socio-economical research extent. The contribution of internal water navigation for such international trade could be surfaced through classical Sinhalese literary works and further supplemented by the archeological findings of ancient water crafts. Three such crafts have been excavated so far, two are now being displayed at Colombo National Museum while one is at Rathnapura Museum. The craft excavated from Attanagalu Oya near Pabovita Raja Maha Viharaya, forms the largest of these three specimens.

The stability analysis of this craft proves its application as a part of a double hull canoe rather than a single, dug-out type canoe. If the larger load to be transported, higher side walls should be provided in order to obtain the required buoyancy and width should also be increased to obtain the required stability. This may lead to the formation of higher amplitude waves, thus increasing the erosion of side banks of the water ways. If the inland water transport 
was extensively used as indicated in historical records, this would have caused a considerable environmental problem in ancient inland water transport systems.

The alternative adopted by our ancestors was to decrease the width and height while increasing the length of the craft. A canoe known as angula was formed by bonding two such crafts, which ensured the transport of high loads while minimizing the erosion effects on the side banks of the water ways.
This phenomena could be compared with the internal water transport modes used in present time. No special crafts are designed for the internal purposes, but crafts designed to ocean transport are used for the purpose if the requirement arises. These oceanic transport crafts are designed to withstand wave and wind movements and their dimensions are optimized to resist those effects. But these may not be suitable for internal water ways as the applicable forces and environmental effects are not as same as ocean transport, thus damaging the ecological sustainability of the internal water ways.

18.2
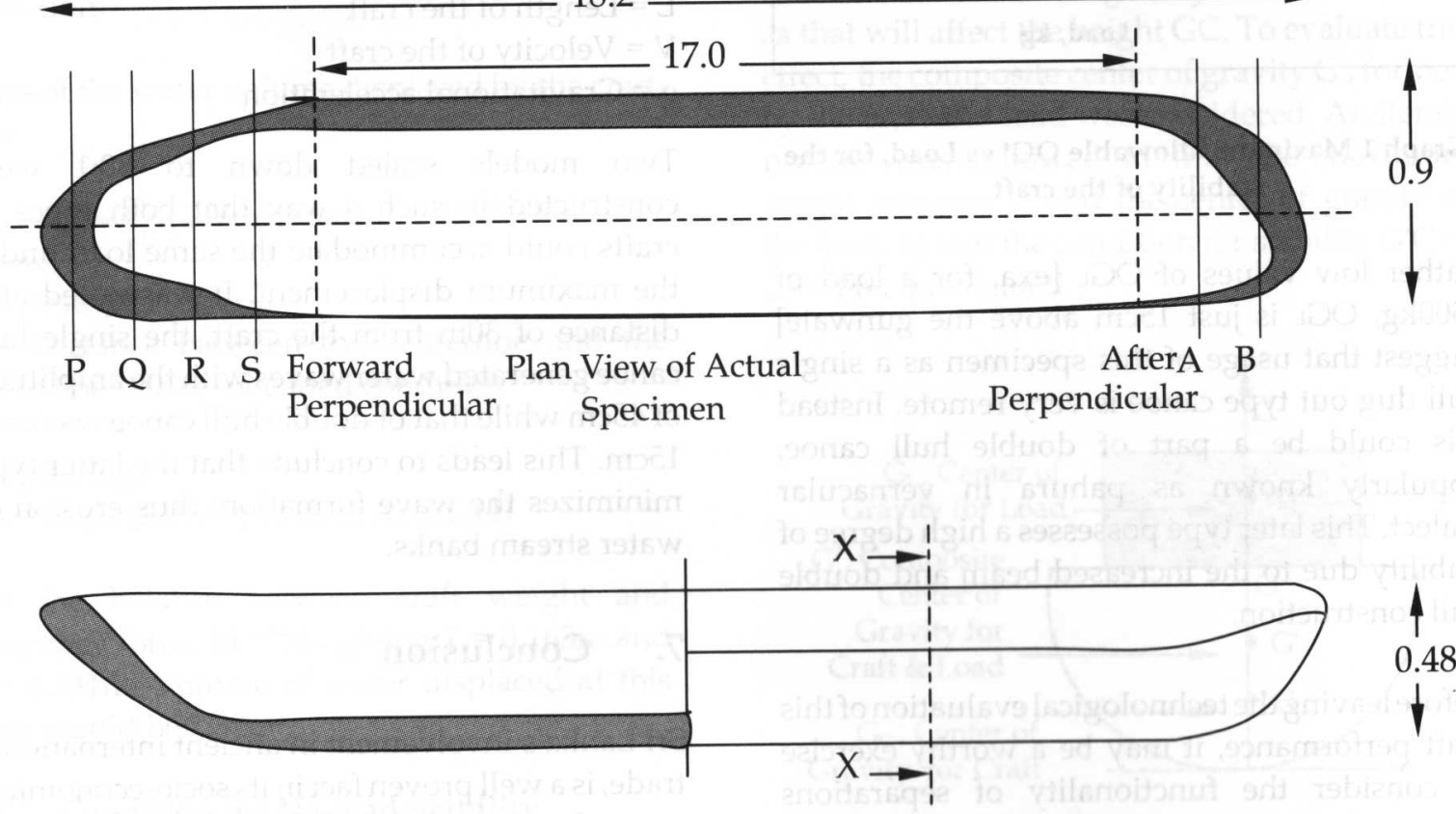

Half Sectioned Front View of Actual Specimen

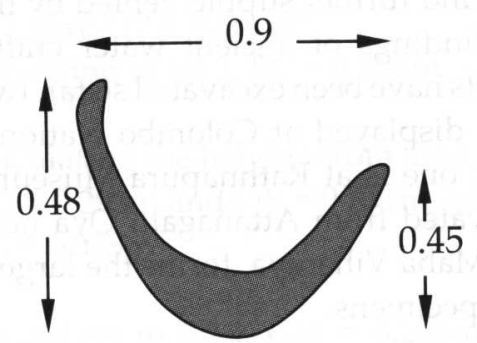

Sectional View on X-X of Actual Specimen

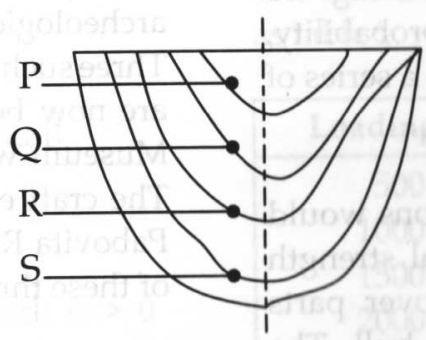

Forward Body Sections (Typical only)

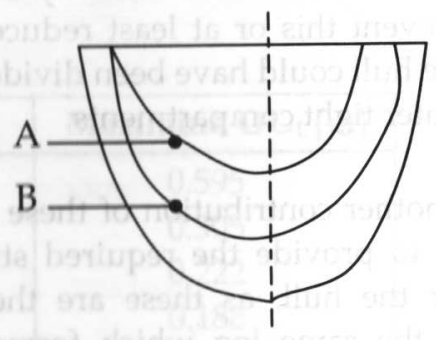

After Body Sections (Typical Only)

Fig 8. Dimensions and Typical Shapes of the ancient craft excavated from the Attanagalu Oya (All dimensions are in meters and not to scale) 


\section{References}

1. Tenant JE (1859), Ceylon: An Account of the Island Physical, Historical and Topographical, $7^{\text {th }}$ Edition, 2006, Thisara Prakashakayo Ltd., Dehiwala, Sri Lanka

2. Gunawardana, RALH (1986), Seaways to Sielediba, Kalyani, Journal of Humanities \& Social Sciences of the University of Kelaniya, Volume V and VI, University of Kelaniya, Sri Lanka

3. Bopearachchi O (2001), Ancient Sri Lanka: New Archeological Data of the Trade between Rome and China, Men and Monuments, Central Cultural Fund, Sri Lanka.

4. Vitharana V (1992), The ORU and the YATRA, Traditional Out-rigger Water Craft of Sri Lanka

5. Mendis DLO (2008), Science and Civilization in Sri Lanka, Annual Transactions of IESL, 2008, The Institute of Engineers, Sri Lanka

6. Muckle, W (1975), Naval Architecture for Marine Engineers, Newnes - Butterworth, London 